\title{
Compassionate Love: Bearing Transcendence
}

\author{
Paul Moyaert *
}

Abstract

The view that charity consists in an expansion of existing interpersonal relations is rather misleading. We need to see it as a radical transformation, of existing relations, even if this suspension is only temporary. In charity we see a person as someone who is no longer capable of reacting appropriately. Someone who is no longer capable of behaving as a 'person' nevertheless continues to be a person. She does not lose her personal sanctity or dignity even if she has lost a practical grasp on controlling and guiding the course of her life.

Today we often tend to reduce charity to a compassionate form of helping, or aid-giving, such as when materials, doctors and psychologists are sent to regions that are torn apart by war or famine. It is much easier to understand charity when it can be measured against the reduction of physical and emotional distress. It is much more difficult to understand charity in cases where aid proves to be powerless, when there is no measurable return or change that is brought about.

While ethics cannot teach us what to do once compassion, benevolence and forgiveness fail to make any difference, prayer can help us to move forward. Praying for others, more specifically, the long-suffering involved in prayer, is a particularly important form of charity. It has the power to lift us above our inability to do anything helpful. We pray at the very moment when we experience our powerlessness to help.

* Professor, The Institute of Philosophy, KU Leuven, Belgium; paul.moyaert@hiw.kuleuven.be 
This article is a journey through the complex interplay of charity, compassion, moral goodness, self-esteem, social hierarchy, spirituality and prayer.

Keywords: Prayer, Charity, Virtue, Ethics, Spirituality, Religion, Compassion

In her voluminous study, Upheavals of Thought (2001), Martha Nussbaum voices a number of thoughts on charity. She accounts for charity, or compassionate love, as a form of mercy or clemency, or more specifically, from the point of view of the lenient judge. As she writes, "[m]ercy is defined as the inclination of the judgment toward leniency in selecting penalties: the merciful judge will often choose a penalty milder than the one appointed in law for the offense" (p. 365). Nussbaum's interest in charity fits within her moral-philosophical plea for greater compassion, a plea that she directs against philosophers such as Spinoza, who argue that benevolence and humanity should not depend on the vicissitudes of compassion. She draws three arguments from Seneca to support her idea that charity, in the sense of compassion, is an expression of moral goodness. Firstly, mercy is compatible with an aristocratic, virile ideal of self-esteem that, contrary to self-humiliation, affirms one's own power. It is not a sign of weakness that one is unwilling to cause pain; nor does it run contrary to the ideals of aristocratic life. Secondly, leniency is grounded in the deeper insight that human beings are flawed, vulnerable and frail creatures. It shows little human insight to consider individuals as the bearers of beauty and goodness alone. A lack of leniency is therefore incompatible with true love, for compassion accepts the other in his or her frailty. Thirdly, compassion fosters and nourishes the life of the community. Thanks to compassion - and this is still according to Nussbaum - the other is not simply cast away or expelled from the community. Leniency therefore contributes to the restoration of bonds between friends and neighbors, for example, or between parents and their children. Moreover, compassion can create new forms of solidarity as well. The more people practice compassion, the more the community benefits from it. Compassion is altruism carried out in the service of social life. As Nussbaum argues, it is 
an attitude that bears in mind how a community is not supported and shaped by rights and duties alone, but also by generosity. There is no generosity without the law, but as generosity cannot be enforced by the law, it refers to a beyond of the law. While others can certainly evaluate and size up your acts of generosity and compassion, they can never point their finger at you for lacking in compassion.

In my remarks here, the following two claims of Nussbaum will be important: firstly, that compassion ought to be understood in terms of leniency or clemency, and secondly, that its value consists chiefly in fostering and restoring communal life. I assume that, by and large, there will be little disagreement concerning these two claims. In my account here, however, I will argue that the attitude of the lenient judge, on the one hand, and the wellbeing of the community, on the other, fail to put charity in the right perspective. Leniency fails to express the inner core of charity, and the analysis of the relation between compassion and the community is misleading. Don't get me wrong: charitable compassion is a form of altruism - I am not calling this into question. But this does not necessarily imply, as Nussbaum would have it, that this particular kind of altruism is in the service of the community. The effects on the community are secondary, as I would like to argue.

To get a better picture of charitable love, I find myself inspired by what has long been called, in the Christian tradition, the fourteen deeds of charity, which are found in Thomas Aquinas' Summa Theologiae 2a 2ae. [Thomas uses the term eleemosynae]. The physical deeds of charity are feeding the hungry, giving drink to the thirsty, clothing the naked, harboring the foreigner, visiting the sick and the prisoner and burying the dead. The spiritual deeds are teaching the ignorant, counselling those in doubt, consoling the afflicted, admonishing the sinner, bearing with patience those who are troublesome and burdensome, forgiving those who insult you, and praying for all, the living as well as the dead. Though this double list does not serve to explain what charity is, it does offer guiding examples of how a compassionate person acts in certain circumstances.

In Christian spirituality, this list of charitable deeds is also meant to function as a practical guide, or illustration, of how one ought to 
interpret and carry out the command to love one's neighbor. It is a fact that the command to love one's neighbor as oneself is not found in the Christian tradition alone. Not only was it already present in the Old Testament, but it plays a significant role in many other great spiritual traditions as well. What sets Christian neighborly love apart as somewhat peculiar, if not as a form of pure and simple anarchy, is one particular formulation of it, namely, to love your enemies. This is the most counter-natural demand that has ever been laid upon human shoulders. It lacks any possible natural foundation. According to a naturalistic understanding of our moral sensibility, pleasure and pain prefigure what is good and bad. They are not only spontaneous expressions of good and bad - they also function as reliable guides to follow. They are natural expressions of love and hate in the sense that our bodies love what is good, insofar as it is pleasurable, and they hate what is bad and what brings harm to our bodies. To love my enemy is to embrace someone who does violence to me and to what is most precious to me. This attitude goes directly against any natural tendency and is impossible to carry out without redirecting the aggression that you bear towards your enemy against yourself. Christianity is aware of the shocking character of this command and recognizes that it is a thorn in the flesh, a stumbling block or a kind of moral madness that conflicts with the ideals of justice and equity. Criminals need to be punished, not to be loved. It is quite understandable that both Nietzsche and Freud claimed that, with this command, Christianity implanted an infinite guilt right into the very heart of our moral sensibility. There is no correct understanding of this command without the knowledge that it is shocking, counterintuitive and cruel. Whatever you do, it is never enough. And that you didn't do more than you did can only be your fault, for the command doesn't forbid you anything.

It is important to point out that Thomas' list of fourteen charitable deeds does not approach the theme of neighborly love from the question of who my neighbor is. The neighbor is nowhere defined with respect to relations based on friendship, family, race, nation or shared belief, for instance. The existing relations don't function as a reference point for identifying your neighbor. The list rather shows what it means to be a neighbor to someone. The person to whom you are compassionate, toward whom you are neighborly, is 
not the one called 'neighbor'. You are the neighbor to whom you are merciful - not the other way around. This perspective corresponds to the parable of the Good Samaritan. At the end of telling his parable Christ asks: "Which of the three was, according to you, the neighbor of the victim of the robbers".

Let us return to the double list. The list makes immediately clear why the leniency of the judge is much too meager an image to properly figure the complexity of charity. To bury the dead, for example, cannot be seen as a form of clemency or compassion. But there is also a more sophisticated reason for drawing your attention to this particular charitable gesture. The ontological condition of a dead body, or corpse, offers a striking picture of the ontological condition of the living person who is in need and who appeals to my charity. Both the dead body and the living person in need occupy an ambiguous [ontological] 'in-between' position, at once inside and outside the social framework. To understand burying the dead as a paradigm of the work of charity clarifies why charity cannot be reduced to, or understood solely in terms of, its beneficial social impact. To my mind, it is not leniency but patience that constitutes the hard kernel of charitable love. Another word for this patience is longsuffering. Charity is a longsuffering love. What charity suffers is a community's inability to be healed or restored, its internal rupture. It stands in the gap of a tear in the community's social fabric and accepts that the gap, or the wound, between me and my neighbor, cannot be healed. In the second part of my paper I will explain this view on charity in more detail. And in my conclusion, I will suggest in which sense patience, or longsuffering, can draw our attention to the spiritual dimension of charity.

But first - why is burying the dead so instructive, or so clear an illustration, of charity?

\section{To bury the dead: a work of charity?}

It is clear why this specific deed of charity does not fit particularly well within Nussbaum's view of things: neither clemency nor compassion enter into the motive for burying the dead. The reference to this particular deed is philosophically instructive 
insofar as it questions our frequent tendency to reduce any and every kind of altruism to benevolence, to the diminishing of pain and suffering in the world or assisting a person in need. A corpse has no need of assistance; unlike a person in need, a corpse does not suffer any more for their trouble. Of course, from a certain angle, you could argue that the act of burying the dead could be reinserted into a larger altruistic cycle, or a higher, derivative need. You could say, for example, that you are diminishing the pain of the relatives and those who survive the dead. This argument is not very convincing, however, since it leads our attention away from the fact that, in the first instance, you are 'helping' the corpse as such.

This particular deed is not the only one that jars our usual understanding of charity as benevolence, as assisting the needy or relieving suffering. Suffering can affect both body and mind: there is physical suffering, and then there is mental suffering. If we retrace the list of the spiritual deeds of charity, we notice that it refers to deeds that cannot be reduced to an altruistic diminishing of mental suffering, or spiritual aid. Some of them would even seem to have nothing to do with suffering of any sort. Take for example the act of bearing with the troublesome and obnoxious qualities of a person's character. A person with a difficult character does not necessarily suffer from his bad character - [on the contrary, it's everyone else who has to suffer in one way or another]. And what about praying? One [often hears reports of statistical studies confirming the beneficial effects of prayer on the recovery of those suffering injuries and illness. Is this what makes prayer an act of charity, a scientific understanding of its potential effects?] At its root, neighborly, charitable prayer is a fundamentally symbolic gesture that cannot be measured up against any efficacy it may or may not have in aiding a person in need.

Do any of these remarks imply that we need to sever the link between charity and aid, or compassion? That is not necessarily the case, but it does incite us to pay closer attention to the deeper meaning of assisting a person who suffers. In what sense? Helpfulness, or the willingness to help, is associated with servitude and subordination: a person who is subservient makes himself subordinate to the other. This involves the basic attitudes of 
reverence, awe and respect. This reminds us of the deeper spiritual meaning at work in burying the dead, or in any other act of charitable service: burial is a final act of showing respect to and honoring the dead. Instead of servicing the dead man's needs, I serve his or her honor and dignity as a human being.

In honoring a man, or his dead body, we recognize that a person occupies a special place within the world. What this involves is an affirmation, carried to the extreme, of the ontological difference between man and other living creatures, such as animals and plants: out of respect, we affirm and re-affirm this difference, especially in those cases in which the difference is no longer evident, or when it is on the point of vanishing. This is precisely what happens when someone dies. Directly following death, the human face of the deceased is still clearly recognizable on his corpse, but it does not take very long before this recognizable shape disappears and dissolves away. In death, the observable differences between man, animals and lifeless matter disappear. And it is precisely there where this difference dissolves - or where it is annihilated by the cruel indifference of nature - that we reemphasize it by making a symbolic gesture, such as a burial. We re-affirm the difference by covering the dead body with pure, white sand, with a blameless sheet, or by cremating it. In this way, we take the human body into protection from everything that might obliterate the unique value of the human being; we guard this value from everything that might negate the radical difference. To put it somewhat differently, we protect the deceased person from a descent into nothingness, from the anonymous and impersonal forces of nature that would negate his value and level the unique place that he held in the world. By honoring the deceased's body or by serving the honor of the man - we do for his body what it can no longer do for itself: we bestow honor upon it at the very moment that it loses any sense of honor and dignity. But should we not recognize the same meaning, or the same sensitivity to the other's dignity, in the clothing of the naked and other acts of charity? To clothe the naked is to respect the dignity of the body, even if, at the same time, it also serves the bodies' needs for protection from cold and physical harm. While the anonymous powers of nature, such as cold, thirst and hunger, threaten to dishonor human existence, by our physical deeds of charity, we 
restore and re-affirm the body's dignity. Ultimately, charity serves to restore dignity to those suffering under degrading and inhuman circumstances. While helping a person in need alleviates his or her suffering, the deeper metaphysical motive underlying this assistance is this restoration of human dignity. We strive to alleviate suffering because it undermines this dignity. Nussbaum's account fails to appreciate this deeper aspect underlying acts of charitable love, for in her emphasis on mercy and benevolence, she fails to explore the deeper motives behind charitable actions.

From a phenomenological point of view, a dead body occupies the position of an ontological 'in-between', as Agamben would have it. It no longer belongs to life and yet it is not yet pure and simple lifeless matter either. The body of a dead person still resembles the living being that it once was, and yet at the same time, it no longer belongs to the world of the living. Though it no longer participates in the world of shared human meaning, it does not simply drop out of this world either. According to the phenomenology of Freud, the dead body is an uncanny presence, a presence without a proper place: neither is it 'still here among us', nor is it simply 'dead and gone'. It falls both inside and outside our world as a disorienting and uncanny presence: it bears an excess that makes it impossible to reduce to the level of mere lifeless matter, and yet, at the same time, it no longer belongs among the living. The charitable act of burial consists in a recognition of the dead body's peculiar ontological condition with respect to the community.

This peculiar ontological condition casts light upon the human condition as such. But in what sense, precisely? Human beings belong to two worlds at once. We both share a world with each other and, as individuals, we fall beyond the reach of what we share in common. We are both members of a community and beings with no membership. We are all beings without a home, without a land - beings without being. This is what contributes to our sense of loneliness and isolation even when we live together in a world of shared meanings. There is a fundamental loneliness inherent in our existence, a loneliness that can never fully be reduced by communication, interaction, socialization or care. This loneliness explains why no human being ever fully falls together with his membership to a larger social group. The dead body 
reminds us of this deeper loneliness. It makes this hidden solitude visible to us by showing how we fall outside the scope of the world to which we belong, as if we didn't have a proper place, or as if each of us lived in an inhospitable gap that were both inside and beyond the larger community. Nussbaum's account fails to situate charity within this broader metaphysical perspective on the human condition.

Though this notion of being 'in-between' gives expression to our human condition, in ordinary circumstances, this insight is far from being dominant. It remains in the background, passing us by and vanishing the very moment that it emerges. It is ultimately this aspect of our being-human - and not a need, pure and simple - that brutally comes to the fore when someone appeals to my charity. My neighbor calls out to me from that beyond where he or she belongs to nothing and to no one. My charity is aroused by the pitiable and miserable loneliness of the human condition that manifests itself before me. It is not necessary to understand this 'beyond' that I am referring to as a deeper richness or a hidden reality. On the contrary, what it marks is our simple and radical incapacity to be deeply and fully engaged in the world we share together. This brings me back to the theme of patience and longsuffering, or what I call the hard kernel of the charitable attitude.

\section{Spiritual deeds of charity}

Charity is often presented as an expansion upon already existing forms of social interaction, or as a radicalization of what we already do for others. But in what sense are we to understand this expanding movement? The notion of expansion implies an enlargement of the social circle in which we carry out acts of benevolence and compassion. What we are already willing to do for our children, family and friends, or for our fellow citizens, we need to do for others, or for those who do not belong to these circles. This view identifies charity with a love for humankind as a whole. The basic presupposition of this view is that existing interpersonal relations - our relations to children and family, for instance - are already shaped by charity, or that they can already be seen as charitable relations. To put it somewhat differently, in 
this view, charity is not radically different in any way from the spontaneous and natural attitude of benevolence that we already show to others. Indeed, the parable of the Good Samaritan is often explained in this way: we need to broaden the scope of our benevolence to those who don't belong to our community.

While it is undoubtedly true that we need to be charitable towards those who fall outside our circle of familiarity, the simple idea that we need to widen the scope of our altruism doesn't really clarify that much in the end. Why not? The idea that deeds of charity expand upon what is already going on in our interpersonal relations wrongly suggests that these relations themselves already belong under the category of 'charity'. It is only in very specific circumstances that people make appeal on my charity. The view that charity consists in an expansion of existing interpersonal relations is therefore rather misleading. Instead of understanding charity in this way, we need to see it as a radical transformation, or suspension, of existing interpersonal relations, even if this suspension is only temporary in nature.

In order to seize hold of this point, we need to distinguish between two different concepts of personhood, one of which is metaphysical in nature, the other practical. The metaphysical notion of personhood, which Kant and Gaita call the sanctity of the person, refers to the dignity that a person bears regardless of her personal qualities and capacities, of her membership to a given social group, or of her geographical origins and genealogy. The ontological fact that you belong to the human species makes you the bearer of an inalienable dignity. The practical notion of personhood, on the other hand, refers to a personal capacity to understand human meanings and values in an appropriate manner, that is, with respect to the way that people are supposed and expected to act and react in certain circumstances. Someone who, due to a severe disability, is no longer capable of performing deliberate, conscious actions, or behaving as a 'person', nevertheless continues to be a person in the metaphysical sense. She does not lose her personal sanctity, or dignity, even if she has lost a practical grasp on controlling and guiding the course of her life, or of being responsible for her actions. What I have in mind with this practical notion of personhood corresponds to what Strawson has called, in 
his Freedom and Ressentiment, the capability to perform 'reactive attitudes'. What reactive attitudes involve is the supposition that a person is capable of being responsible for his behavior, that he is sensitive to and understands the complex play of motivations and intentions guiding human behavior. To be a person in the practical sense requires that you care about the judgment of others, that you are affected by pride and shame, that you understand the practical significance of guilt, responsibility, repentance, forgiveness and so forth. In the end, it is quite difficult to give a precise definition of these interpersonal, reactive attitudes, and I will not do so here, for practical notions of personhood can be found in a wide variety of forms in many different cultures, and can vary geographically. For our purposes here, let it suffice to understand this practical sense of personhood both as a moral sensitivity to the values and motivations guiding human action and a basis of personal moral responsibility.

Certain examples help clarify what is at stake in the practical notion of personhood. If you assist a person in need, for instance, you are right to expect that he or she will be grateful to you. These sorts of expectations are formed in large part by socialization, such as when we teach a child to be grateful and how to properly express his gratitude. Similarly, we encourage people affected by adversity to conduct themselves with dignity. A person is blamed and reproved when she behaves 'incorrectly' in response to adversity; we assume that she can understand why the action she takes is wrong, why certain excuses are appropriate in some circumstances while inappropriate in others. Underlying these sorts of practical considerations is the assumption that people generally care about what others think about them and about their actions.

Charity, on my view, is practiced at the very moment when a person, for whatever reason, is no longer capable of reacting appropriately, or of fully participating in the interpersonal space of shared human meanings and values. It is wrong to begin by asking the question of who my neighbor is, who it is that demands my charity. The first question that needs to be asked is rather: what are the circumstances under which a person becomes the object of my pity, or charity. And how do these circumstances differ from those 
that condition my normal or more usual way of acting and relating to others? As I would like to argue, charity begins there where I effect a radical alteration to, or suspension of, my attitude toward others - not where I simply expand or enlarge upon this attitude. We will see in a moment what this transformation consists in and what it means. For the time-being I would simply like to emphasize that charity involves more than simply doing something for a person or helping her in some way or another; more than that, it is inextricably bound to an abandonment of the spontaneous attitude that we bear with relation to others, an abandonment that nevertheless holds back from fully severing itself off from its spontaneous attitude. What it involves is a suspension, however temporary, of our practical sensitivity to 'personhood' and the needs of others - not an expansion thereof.

[Charity starts with the necessity to give up our spontaneous demand that a person reacts as a person. To help a person in need is an act of charity/compassion at the very moment that the person in distress is no longer capable of reacting appropriately to the aid he/she receives. In charity we see a person as someone who is no longer capable of reacting appropriately. Basically, charity is all about interrupting, suspending and postponing the usual or habitual forms of interacting with each other. Charity is not an expansion (enlargement) of the existing forms of inter-subjectivity, but a transformation/modification of them. The modification also exists in an interruption (suspension) of our spontaneous expressions of altruism and benevolence.]

It should be clear how this understanding of charity falls right in line with what we discussed earlier concerning burying the dead. The person toward whom you are charitable - in this case a dead body, or a 'person' lacking any sense of practical personhood - falls both within and beyond the reach of our normal, socialized, interpersonal relations. Charity acts based on the insight that the person in need is at least temporally inaccessible as a person, as if the practical notion of personhood had lost its grip on him or her. As long as a person is actually engaged in the practical field of human meanings and appropriately responds to these meanings, charity cannot and need not come into play. Charity is not a plea for more openness or sensitivity to the conditions that make the 
person different or socially inaccessible; no, it arises from the insight that the other can no longer take part in interpersonal interaction. What causes someone to fall beyond the reach of interpersonal reactive attitudes is his human misery, his poverty, his incapability to fully participate as a person to the demands of life. The hard kernel of the charitable attitude is to bear with this poverty and incapability, just as Christ bears witness in his prayer on the cross: "Father, forgive them for they don't know what they are doing" (Luke 23:34).

It is a mistake to understand charity as involving a constraint on our egoism, for what needs to be constrained in charitable love is not so much our egoism as the spontaneous reactive attitudes that frame and organize our relations to others. I behave with cruelty when, in performing an apparently charitable action, I cannot stop myself from exhorting the other to react in certain ways, to behave as a responsible moral agent, or as other persons do. Why is it so difficult to abandon these attitudes of moral encouragement, exhortation, incitement and so on? The answer: because reactive attitudes constitute what it means to be, to live and to act as a person. Charity, in contrast, moves in a sort of in-between, between the demands that we place upon the other to react as a person and the suspension, or temporary neutralization, of these demands.

It is easy to see how this notion of charity as a suspension of the normal, interpersonal reactive attitudes hangs together with the practice of patience or longsuffering. Charity is a patience that bears with the transcendence of a person. (This definition goes back, of course, to Paul, who, in 1 Cor. 13: 4, writes that love is patient and kind, that it is not boastful or arrogant). One important consequence of my clarification of charity is that actions such as teaching the ignorant, consoling the distressed and advising those in doubt cannot, in and of themselves, be seen as deeds of charity. On the contrary, these are actions that we carry out spontaneously; they are the basic equipment with which we relate to and recognize each other as persons, in the practical sense of the term. What is it, then, that transforms these actions into deeds of charity?

- Counselling those in doubt becomes a deed of charity when the doubter gets trapped, or stuck, within her indecisive 
attitude; when she, despite her openness to and explicit demand for advice, cannot pay heed to any advice whatsoever. Insofar as she asks for advice, she falls within interpersonal relations, but because she remains captive to her lack of resolution, she falls outside these relations at the same time. Every bit of counsel she receives 'falls on deaf ears', as we say. She becomes the object of my charity precisely when this deafness falls upon her, when she finds herself withdrawn and closed off from the advice she is nevertheless desperately seeking out. Charity, in this instance, consists in enduring with the hopeless lack of resolution of those in need of counsel.

- Take next the act of consoling those in distress. This becomes a work of charity at the very moment when, in spite of a person's demand for and desperate need of consolation, she remains totally impervious to consoling words and gestures. I become a neighbor to her at the very moment when she becomes a captive of her inconsolability and when I, in turn, am forced to bear with my powerlessness to console her.

- Or take yet another example, the forgiveness of offenses. Without further conditions, I would hesitate to call this a work of charity. To forgive an offense is not a charitable act, if, for example, the forgiveness comes as a response to the other's sincere expression of regret. Both repentance and forgiveness belong to our spontaneous moral attitudes. Forgiveness only becomes charity when it takes the shape of a simple, longsuffering bearing-with, when one endures the offense as such. Here my view no doubt deviates somewhat from Christian tradition, for in my view, charity does not involve a willingness to forgive ever greater offenses, or a continual turning of the other cheek. In my view, charity consists much less in forgiving the unforgiveable as in enduring the fact that we cannot forgive everything. Instead of necessarily seeking out the restoration of the community, it endures the pain that has been caused to the community by what cannot be forgiven. Charity accepts the fact that the community will never be 
fully free of strife and division, that the community can be touched by wounds that cannot be healed, by sins that cannot be forgiven.

There are extreme circumstances in which we have to accept the fact that we can no longer help a person, in which nothing we do can ameliorate the delicate 'in-between' situation in which the other finds herself. These are circumstances in which we run up against a radical limit to our benevolence and compassion, when the properly charitable dimension of forgiveness reveals itself its powerlessness. Though these might be rather rare and exceptional circumstances, it is nevertheless instructive to reflect on charity in light of them.

What can charity do in these extreme conditions? The answer seems rather obvious: the only thing charity can do is to endure with longsuffering, to bear with the fact that consolation (or forgiveness) can no longer help. Today we often tend to reduce charity to a compassionate form of helping, or aid-giving, such as when materials, doctors and psychologists are sent to regions that are torn apart by war or famine. The reason for this is that it is much easier to understand charity when it can be measured against the reduction of physical and emotional distress suffered by those to whom aid is directed. It is much more difficult to understand charity in cases where aid proves to be powerless, when there is no measurable return or change that is brought about, such as we saw in the examples from a moment ago. But is there still something that we might be able do in these sorts of cases? Is there something else we could do beyond merely accepting the irremediable aspects of the situation and bearing with them? In short, is there something else at work in charity beyond the practice of a long-suffering patience?

From a secular point of view that identifies charity with aid, to practice a long-suffering attitude would seem to be the only course of action left open. By reflecting on the nature of prayer as a form of spiritual labor, however, we should be able to open up another perspective, a perspective that remains hidden when charity is approached in ethical and moral terms alone. By turning to prayer, 
we should be able to see that charity involves something more than merely bearing-with its own powerlessness.

\section{Praying: A Gesture of Charity}

Reflection on prayer takes us into the metaphysical and spiritual heart of charity. In social life, we spontaneously approach and relate to each other as being open towards the good, or as being accessible to the light of goodness. In a similar way, we instinctively hold each other accountable for our actions. We cannot abandon questions concerning the guilt and responsibility that we bear for our actions without going against our moral nature. Attitudes relating to the question of personal responsibility and guilt form the hard core of our moral life - the question itself is constitutive of what it means for us to be moral agents. Usually, we don't pay attention to this a priori structure of our moral sensibility.

We only become aware of this attitude, which silently guides and shapes our moral life, when we notice someone who is no longer capable of sharing in it. We already know what these circumstances are: circumstances in which feelings of pride and shame lose their grip on a person, when consoling words reveal their powerlessness, or when, in spite of our encouragement and admonishment, a person remains clouded in doubt and fails to act. Confronted with these sorts of situations, we cannot help asking who is responsible for them, who is responsible for the break, rupture or failure. Whose fault is it that a person can no longer be affected by the good? Involuntarily, a desperate search for responsibility and guilt takes over in us. Our demand to understand, or somehow to reconcile the situation, imposes itself on us as we bump up unexpectedly against the limits of the good. There aren't very many answers or solutions to be given here. Either we take the person who is closed off from the good as being responsible, and if need be, we compel him in one way or another to behave as person, to take responsibility for himself and so on. $\mathrm{Or}$ we accuse ourselves: ' $I$ have to be still more forgiving, more benevolent, more in tune with the other's suffering.' It is hard to make peace with the fact that, ultimately, no one bears responsibility. Our moral sensibility doesn't allow us to free ourselves so easily from this perspective. As a result, we 
continually shift back and forth between blaming ourselves and blaming the other, between redoubling our efforts, on the one hand, and discounting our failures with a good measure of the other's guilt, on the other hand.

It is a moral shock to run up against the limits of the good and the useful, or the helpful. It is shocking to discover that goodness is limited and cannot penetrate everywhere. As we run up against these limits, we encounter a violent resistance welling up from the moral perspective that is made inoperative, or that is thereby put out of action. This is a violence coming from ethics as such, a sort of stubborn, impotent rage that cannot tolerate the limited power of the good. Charity exhorts us to lay down the weapons of this violence and inspires us to patience and longsuffering, to an attitude that occupies the uncomfortable limit-position between doing something and not doing anything, or between activity and passivity. In this sense, we can say that charity neutralizes what is essential to ethics, or that, with charity, we move beyond of our basic moral categories. Longsuffering patience is in-between passivity and activity. It is not pure and simple indifference, because it deplores the limits against which the good bumps up; and yet, at the same time, it restrains itself from any form of therapeutic or charitable 'forcing' that would attempt to overcome these limits. In this new attitude, which only comes into the foreground when our moral categories are rendered inoperative, the other appears in a new light, namely as someone who is both responsible and not responsible. Insofar as charity suspends ethics, it is more generous, tender and lenient than ethics. At the same time, however, it is also more cruel than ethics, for the patience that it demands is rooted in an insight of the limits of the good.

But when charity brings us to rise above our spontaneous moral attitude, how do we know what we need to do in this selftranscending movement? Does our moral practice know how to act once our basic categories have been neutralized? Does it teach us what to do when we run up against the limits of our actions? Allow me to put it somewhat differently. We have all learned that we need to help those in need and to forgive those who wrong us, but do we know what to do when we run up against the limits of 
compassion and forgiveness? Do we need to further strengthen our will to help others, to blame either them or ourselves when this strengthening comes to grief? Or do we need to neutralize such efforts and accept such limitations? Is this the only alternative: either to persevere, almost out of sheer stubbornness, or to accept our finitude?

Spirituality teaches us that there is a third alternative, namely prayer. Praying for others and, more specifically, the long-suffering involved in prayer, is a particularly important form of charity. It has the power to lift us above our inability to do anything helpful. We pray at the very moment when we experience our powerlessness to help. While ethics cannot teach us what to do once compassion, benevolence and forgiveness fail to make any difference, prayer can help us to move forward. Through prayer, we ask for the very help that we, finite as we are, cannot offer anymore. This is aid that we ourselves are incapable of offering, an aid that must come from elsewhere, namely, from God's charity. In praying, we ask God to do for the person in need what we ourselves are powerless to do, limited as we are. Prayer thus involves more than an attitude of long-suffering patience, for in it, we do something for the person in need at the very moment that we no longer know what to do. In the practice of spiritual patience, which charitable acts such as prayer exercise, the three basic Christian virtues come together: infinite hope, faith and love. 